\title{
A retrospective case series of rupture uterus during five years period at a rural medical college in West Bengal, India
}

\author{
Kajal Kumar Patra ${ }^{1}$, Apurba Mandal ${ }^{2}$, Shibram Chattopadhyay ${ }^{3}$, Arunava Biswas ${ }^{4}$, \\ Siddhartha Majumder ${ }^{5}$ \\ ${ }^{1}$ Professor, Department of Gynaecology and Obstetrics Lord Buddha Koshi Medical College, Saharsha, Bihar, India, \\ ${ }^{2}$ Associate Professor, Department of Gynaecology and Obstetrics, Coochbehar Government Medical College and \\ Hospital, Coochbehar, West Bengal, India, ${ }^{3}$ Associate Professor, Department of Gynaecology and Obstetrics, Nil Ratan \\ Sirkar Medical College and Hospital, Kolkata, West Bengal, India, ${ }^{4}$ Associate Professor, Department of Pharmacology, \\ Coochbehar Government Medical College and Hospital, Coochbehar, West Bengal, India ${ }^{5}$ Assistant Professor, \\ Department of Gynaecology and Obstetrics, ESIC-PGIMSR Medical College \& Hospital, Kolkata, India
}

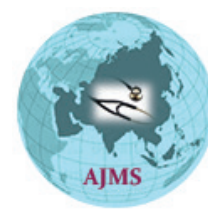

A B S TR A C T

Background: Rupture of the uterus carries major risk of maternal and perinatal morbidity and mortality especially in the developing world. Aims and Objectives: This study aims to identify retrospectively the risk factors leading to uterine rupture through case series and to determine the feto-maternal outcome of such serious clinical condition. Material and Methods: A retrospective study was done at Bankura Sammilani Medical College, Bankura, West Bengal, India from January 2014 to December 2018 to observe the incidence, aetiology, management and complications with maternal and foetal mortality and morbidity associated with rupture of the uterus in pregnant women at different gestational periods. The data were obtained from the case record section of the hospital. All rupture uterus cases were included excluding the dehiscence of scarred uterus. Results: Twentyone cases of Rupture Uterus were documented out of total delivery of 43,323 mothers in five years. There was a single maternal death and $15(71.42 \%)$ unbooked cases. Previous mode of delivery was found to be vaginal in 5 cases $(23.8 \%)$. Most of the incidences of rupture uterus were scarred uterus (previous caesarean section and repaired uterus) 16 cases $(76.19 \%)$, prolonged / obstructed labour 4 cases (19\%), inductionof labour $1(4.76 \%)$ and spontaneous rupture $1(4.76 \%)$. Most cases were multiparous; site of rupture was in lower uterine segment in 18 cases $(85.7 \%)$, fundal rupture 2 cases $(9.52 \%)$ and left lateral 3 cases $(14.2 \%)$. Bladder injury was in 1 case (4.76 \%). Total abdominal hysterectomy was performed in 2 cases $(9.52 \%)$ andsubtotal hysterectomy were done in 15 cases $(71.4 \%)$; repair of the ruptured uterus wasperformed in 4 cases (19\%). Fever and wound infections were present in 5 cases (23. 8\%). Maternal death $1(4.76 \%)$ and 3 babies survived with perinatal mortality $18(85.7 \%)$. Conclusion: Mandatory antenatal care, prompt diagnosis and safe instrumental delivery may change the rupture uterus incidences.

Key words: Uterine scar; obstructed labour; maternal and perinatal morbidity and mortality

\section{INTRODUCTION}

Rupture of the uterus is a catastrophic event jeopardising the life of both mother and fetus. It carries even more risks when dehiscence or rupture occurs in a place where proper medical facilities of blood transfusion, anaesthetist,

\section{Access this article online}

Website:

http://nepjol.info/index.php/AJMS DOI: 10.3126/ajms.v12i2.31019

E-ISSN: 2091-0576

P-ISSN: 2467-9100

Copyright (c) 2021 Asian Journal of Medical Sciences

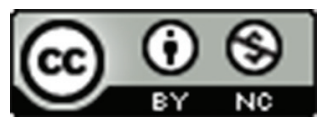

This work is licensed under a Creative Commons Attribution-NonCommercial 4.0 International License. 
cephalo-pelvic disproportion with obstructed labour is the major cause of rupture uterus. ${ }^{4-6}$

In the developed countries, the incidence of rupture was cited by Getahun and associates in 2012 as 1 in 4800 deliveries. ${ }^{7}$ Rupture of the uterus due to obstructed labour has been reduced but total uterine rupture incidents has not been changed due to increased incidence of caesarean section (scar rupture). ${ }^{8}$ The different modes of management in such emergency situation are repair of uterine scar or total and subtotal hysterectomy. The main objective of this retrospective case study was to find out the changing incidence, cause, management and outcome of rupture uterus in a rural medical college and hospital scope of improving the result in future.

\section{MATERIALS AND METHODS}

All the case records of rupture uterus managed in the obstetrics department from January 2014 to December 2018 were obtained from Bankura Sammilani Medical College Hospital, Bankura, West Bengal. The Institute Scientific Research Committee's approval was obtained before initiation of the study. The age, parity, booking status, past history of caesarean section, details of labour, type of rupture (complete/incomplete), treatment (repair/ hysterectomy), blood transfusion and condition of the foetus (alive /dead), postoperative complications, maternal mortality were collectedin data collection form. The total number of deliveries occurred within that period was also recorded and any rise in its incidence was analysed.

Rupture uterus was labelled as complete when the entire thickness of the uterine wall along with the visceral peritoneum gave away irrespective of the extrusion of foetal parts. Cases which were recorded as dehiscence were left aside and not included in this study. All data were subsequently statistically analysed in Microsoft Excel 2010.

\section{RESULTS}

There were $(\mathrm{n}=21)$ cases of rupture uterus as per record occurred among 43,323 deliveries between Jan 2014 to Dec 2018 with the incidence of $0.048 \%$. Among the cases included in this study, 15 were unbooked $(71.42 \%)$ and referred from peripheral health centres which are situated in remote areas. There was one case of maternal death $(4.76 \%)$. Regarding baby outcome, of the 21 cases 18 died and 3 babies survived.

Table 1. shows the patient particulars, in which 15 cases were unbooked $(71.42 \%)$, and in 16 cases $(76.10 \%)$ uterine rupture occurred mainly during 36-39 weeks of gestation.
From the past history of the cases of uterine rupture it was found out that majority of cases occurred in scarred uterus due to previous caesarean section $(66.60 \%)$ for a non-recurrent cause.

In Figure 1. most cases (47.61\%) were in the age group of 21 to 25 years. There were 5 grand multiparous patients who had previous 5 or more deliveries and majority of the cases included in this study were of patients who were third para $(42.85 \%)$. There was no primi parous patient in this study.

Table 2. shows that the most common causes of rupture uterus in patients with previously scarred uterus $(76.19 \%)$, which was seen $66.6 \%$ in previous caesarean deliveries and $9.52 \%$ in previously repaired uterus. Previous caesarean deliveries were mostly done due to non-recurrent causes. In cases where uterus was not previously scarred, causes were CPD (4.76\%), obstructed labour (14.8\%) and prostaglandin induction $(4.76 \%)$.

Amongst the 16 patients with scarred uterus 11 cases were in labour at the time of admission and in 5 cases of uterine

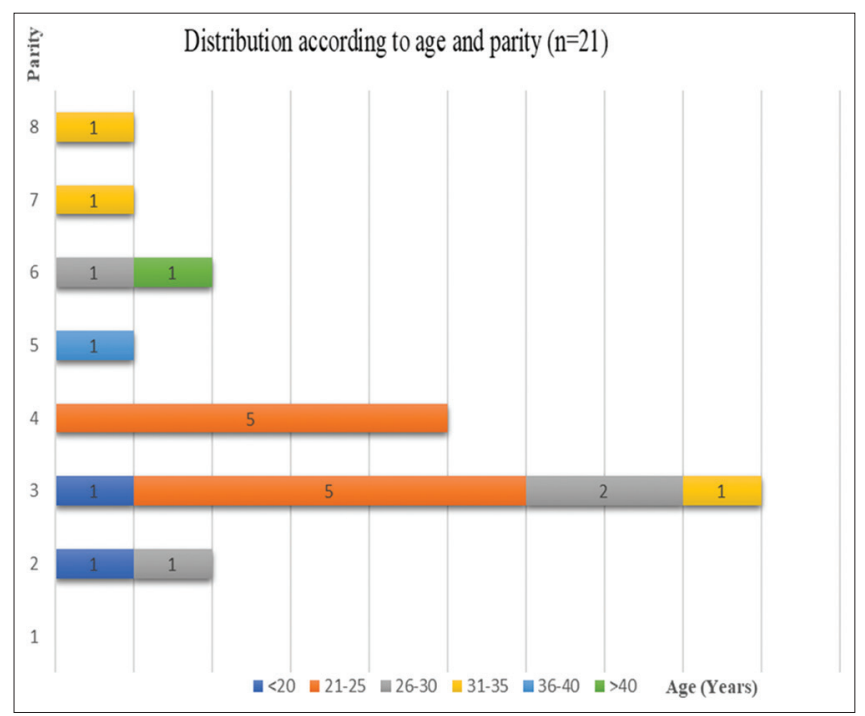

Figure 1: Comparison between parity and age of the mothers $(n=21)$

\begin{tabular}{|c|c|c|c|}
\hline \multicolumn{2}{|c|}{ Patient particulars } & \multirow{2}{*}{$\begin{array}{c}\text { Cases } \\
6\end{array}$} & \multirow{2}{*}{$\begin{array}{c}\text { Percentage } \\
28.57 \%\end{array}$} \\
\hline Booking & Booked & & \\
\hline status & Unbooked & 15 & $71.42 \%$ \\
\hline \multirow{5}{*}{$\begin{array}{l}\text { Gestational } \\
\text { age in } \\
\text { weeks }\end{array}$} & 40 & 1 & $4.76 \%$ \\
\hline & $36-39$ & 16 & $76.10 \%$ \\
\hline & $32-35$ & 2 & $9.52 \%$ \\
\hline & $28-31$ & 1 & $4.76 \%$ \\
\hline & $<28$ & 1 & $4.76 \%$ \\
\hline \multirow{4}{*}{$\begin{array}{l}\text { Mode of } \\
\text { previous } \\
\text { deliveries }\end{array}$} & Vaginal delivery & 5 & $23.80 \%$ \\
\hline & Previous 1 caesarean delivery & 14 & $66.60 \%$ \\
\hline & Previous 2 caesarean delivery & 1 & $4.76 \%$ \\
\hline & Classical caesarean section & 1 & $4.76 \%$ \\
\hline
\end{tabular}

Asian Journal of Medical Sciences | Feb 2021 | Vol 12 | Issue 2 
Table 2: Causes of rupture uterus and operative interventions under taken

\begin{tabular}{|c|c|c|c|c|}
\hline Parameters & & & Cases & Percentage \\
\hline \multirow[t]{5}{*}{ Causes of rupture uterus } & Unscarred uterus $(23.80 \%)$ & CPD & 1 & 4.76 \\
\hline & & Obstructed labour & 3 & 14.28 \\
\hline & & Prostaglandin induction & 1 & 4.76 \\
\hline & Previous scar (76.19\%) & Caesarean delivery & 14 & 66.6 \\
\hline & & Repaired rupture uterus & 2 & 9.52 \\
\hline \multirow[t]{4}{*}{ Operative interventions } & Hysterectomy & Subtotal & 10 & 47.61 \\
\hline & & Total & 3 & 14.28 \\
\hline & Associated surgeries & Bladder Repair & 4 & 19.04 \\
\hline & & Internal iliac ligation & 2 & 9.52 \\
\hline
\end{tabular}

rupture was suspected. Among others, two patients were such, in whom rupture of repaired rent in a multigravida took place (who were not in labour). Among 5 unscarred uterus 3 patients had obstructed labour and none had history of medical termination of pregnancy. No case of rupture was due to misoprostol induction as it is banned by government.

Table 2 shows that in $47.61 \%$ cases subtotal hysterectomy took place and other associated surgeries such as simultaneous bladder repair was done in $19.04 \%$ cases.

Table 3 shows that among post-operative complications, wound infection $(9.52 \%)$ and paralytic ileus $(9.52 \%)$ were the most common which were treated conservatively. Ten patients $(47.61 \%)$ recovered from the operation uneventfully. There was only one case of maternal death, this patient was referred from a health centre in labour and admitted in a state of shock. Perinatal mortality was high $(85.71 \%)$; there were 3 cases of intra uterine foetal death (IUFD) in whom foetal heart sound was not detected before operation, although three babies (14.28\%) survived among the rest asphyxiated babies and 15 babies died eventually despite resuscitative measures. Table 4 also shows that rupture was confined to lower uterine segment in 14 cases $(66.67 \%)$, upper uterine segment in 2 cases $(9.52 \%)$ and 5 in lateral wall $(23.8 \%)$.

\section{DISCUSSION}

Since rupture uterus is a major risk for the health of mother and child a retrospective case series was attempted in a rural medical college. The series of rupture uterus observed in the present study was 21 out of 43,323 deliveries ( $0.048 \%)$ during the specified 5 years period which was very low in comparison to study by Bandopadhyay S et al.(0.061\%). ${ }^{8}$ There was maximum number of ruptures in scarred uterus 16 cases $(76.1 \%)$ than non-scarred uterus. This was in contrast to study conducted by Naik et al. ${ }^{9}$ where majority were unscarred uterus.

\begin{tabular}{|c|c|c|c|}
\hline & Types & Cases & Percentage \\
\hline \multirow{6}{*}{$\begin{array}{l}\text { Post- } \\
\text { operative } \\
\text { complications }\end{array}$} & Wound infection & 2 & $9.52 \%$ \\
\hline & Bladder injury & 4 & $19.04 \%$ \\
\hline & Wound dehiscence & 1 & $4.76 \%$ \\
\hline & Paralytic ileus & 2 & $9.52 \%$ \\
\hline & Secondary PPH & 1 & $4.76 \%$ \\
\hline & Mortality & 1 & $4.76 \%$ \\
\hline \multirow[t]{3}{*}{ Site of rupture } & Lower uterine segment & 14 & $66.67 \%$ \\
\hline & Upper uterine segment & 2 & $9.52 \%$ \\
\hline & Lateral & 5 & $23.80 \%$ \\
\hline
\end{tabular}

Rashmi et $\mathrm{al}^{6}$ showed rupture in scarred uterus 1 in 485 deliveries and $90 \%$ had a poor antenatal check-up. One patient received oxytocin drip and no cases was given misoprostol for induction, 18 patients had a history of previous caesarean section (CS)and admitted with rupture uterus.

In a resource constrain setup it is impossible to admit all post caesarean pregnancies routinely at 38 weeks of gestation. Induction of labour is not done unless having IUFD or pre term pre mature rupture of membrane. Patients are subjected to vaginal birth in post CS cases when conditions are satisfactory with adequate supervision and lower segment caesarean section (LUCS) done previously. The overall incidences of CS in the institute found to be around 38\% which signifies the greater trend of vaginal delivery. Patients catering from rural areas of Bankura district of West Bengal and their as well as family member's lack of awareness about proper antenatal care, unable to judge the emergency situation of pregnant mothers and subsequent referral are probably some of the factors that according to the authors are contributing behind such untoward incidences of rupture uterus.

Delay in detecting deviation from normal going resulted in rupture uterus in intrapartum period both in cases of previous caesarean mothers as well as multiparae having induction of labour for rupture of membranes or augmentation of labour.? 
In the present study going through the hospital records it was observed that documents of previous LSCS are lacking in many cases. We should have to be more cautious about operating primary LSCS in properly indicated cases with proper technique to lower future gestational complications. Judicious use of partogram and timely monitoring of primi or multiparous mothers can prevent many unwanted future catastrophes. The high-risk pregnant women and their family members should adequately and appropriately made aware and conscious about their health condition, need for thorough antenatal checkup and prompt admission to hospital if necessary. There is a need of proper supervision of patients in labour with partogram and planned mode of delivery in scarred uterus.

\section{CONCLUSION}

Uterine rupture is a vital factor to maternal morbidity and neonatal mortality. Four paramount doubtlessly identifiable risk factors including history of prior caesarean section, grand multiparity, obstructed labour, and foetal malpresentations account for most cases of uterine rupture. Recognition of these high-risk women, timely diagnosis, expedited transfer, and favourable management needs to be overemphasized to avoid adverse feto-maternal complications. Utmost caution should be taken when managing patient with an earlier uterine scar, seeking a trial of labour. Escalated accessibility to superior obstetric care and prompt referral system to better facilities with availability of transportation services is essential for developing countries to avoid these devastating emergencies.

\section{REFERENCES}

1. Leung AS, Leung EK and Paul RH. Uterine rupture after previous cesarean delivery: Maternal and fetal consequences. Am J Obstet Gynecol. 1993;169,945-950. https://doi.org/10.1016/0002-9378(93)90032-E

2. Saglamtas M, Vicdan K, Yalcin H, YilmazZ, Yeşilyurt H and Gökmen O. Rupture of the uterus. Int J Gynaecol Obstet 1995;49(1); 9-15. https://doi.org/10.1016/0020-7292(95)02333-8

3. Gardeil F, Daly $S$ and Turner MJ. Uterine rupture in pregnancy reviewed. Eur J Obstet Gynaecol Reprod Biol 1994;56(2);107-110. https://doi.org/10.1016/0028-2243(94)90265-8

4. Diallo FB, Idi N, Vangeenderhuysen, Baraka D, Hadiza I, Garba M, et al. Uterine rupture at the Niamey Central Maternity Reference Centre, Nigeria. Dakar Med 1998;43(1):74-78.

5. Gessessew A and Melese MM. Ruptured uterus-eight-year retrospective analysis of causes and management outcome in Adigrat Hospital, Tigray region, Ethiopia. Ethiop J Health Dev. 2002;16(3): 241-245.

https://doi.org/10.4314/ejhd.v16i3.9792

6. Rashmi G, Radhakrishnan N, Vaid B and Agarwal N. Ruptureuterus - changing Indian Scenerio. J Indian Med Assoc.2001; 99(11): 634-637.

7. William obstetrics $24^{\text {th }}$ edition(e-book). Rupture of the Uterus. 2012. p:790-792.

8. Bandyopadhyay S and Singh S. Rupture uterus: a clinical analysis. Int J Reprod Contracept Obstet Gynecol. 2016; 5: 2183-2186. https://doi.org/10.18203/2320-1770.ijrcog20162089

9. Naik B, Gohil JT and Pagi SL. Rupture uterus: A 12 years review. J Obstet Gynaecol India. 1996;46(3):334-340.

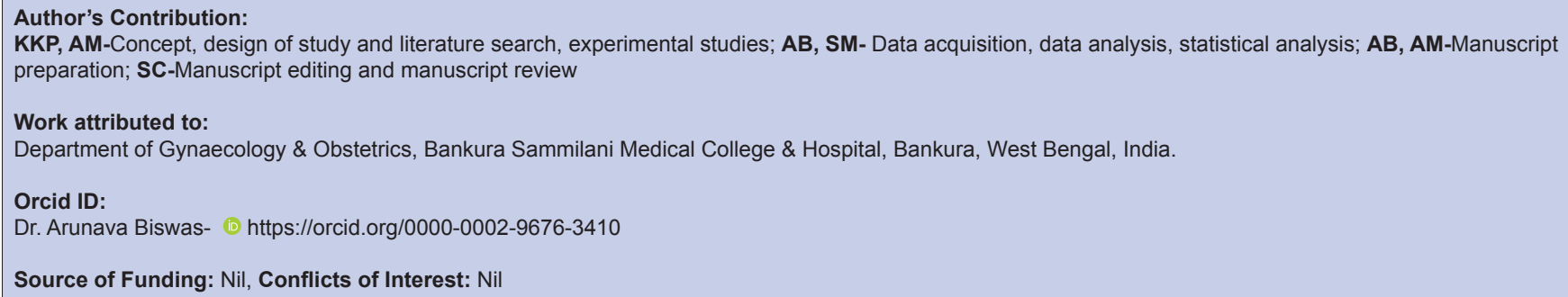

